\title{
Contribución a la epigrafía del Oeste de la provincia de Salamanca. El conjunto de Medina del Campo (Valladolid)
}

A. Jiménez de Furundarena, L. Hernández Guerra y T. Mañanes Pérez *

\section{INTRODUCCIÓN}

A finales del verano de 1991 estudiamos una colección particular de 28 epígrafes romanos depositados en una casa de campo próxima a la localidad de Medina del Campo'. Los epigrafes proceden de una gran necrópolis romana situada en un cerro llamado Cabeza de San Pedro, en el término municipal de Hinojosa de Duero (Salamanca) ${ }^{2}$, junto al salto de Saucelle, durante cuya construcción - fue inaugurado en 1956- pasaron estas lápidas a manos de particulares.

El objetivo de este trabajo es, pues, hacer algunas referencias y puntualizaciones sobre todo el conjunto de epigrafes de Hinojosa de Duero, relacionándolo con la epigrafía de algunas localidades, como Astorga o Chaves, y de algunas regiones, como la comprendida entre los rios Duero y Sabor, la zona zamorana y el occidente salmantino.

Hinojosa de Duero está enclavada en la comarca salmantina de los Arribes del Duero, al extremo de la penillanura de Salamanca ${ }^{3}$, formación que es una parte del viejo zócalo Herciniano peninsular y que fue basculado hacia el Oeste por los movimientos orogénicos Terciarios. Las ro-

* Univ. de Valladolid.

Mananes, T.: Hernandez Guerra. L. y Jimenez de Furundarena, A., "Un conjunto epigráfico inédito de Medina del Campo (Valladolid)", HA, XVI. 1992, págs. 273-308.

Maluquer de Motes, J., Carta Arqueológica de España. Salamanca. Salamanca 1956, pág. 68.

Cabero Dieguez, V.: Cascos Marana, C. y Calonge Cano, G. Los espacios Naturales, vol. III de la Geografia de Castilla y León. Valladolid. Ed. Ámbito. 1987. pags \$1.14 
cas predominantes en esta zona de la penillanura son el granito y la pizarra. Por el Oeste, el borde de la penillanura está profundamenta erosionado por el río Duero, que para descender desde la Meseta hacia las llanuras portuguesas excava a lo largo de la frontera Hispano-Lusa un gran cañón de más de $300 \mathrm{~m}$ de profundidad y pendientes de unos 50 grados, cañón que separa netamente las provincias españolas de Zamora y Salamanca del Tra-os-Montes portugués. La orilla portuguesa - Sierra de Mogadouro- es más elevada que la española. El río Duero recibe como afluentes al río Tormes, procedente de Salamanca y el Macizo Central de la Sierra de Gredos, y algo más al Sur al río Huebra, procedente de la Sierra de Gata, al igual que su afluente el Yeltes. Estos ríos también excavan cañones a medida que se aproximan a su desembocadura en el Duero. Excepto estas profundas cortaduras, la llanura es plana, aunque la intrusión de granitos más duros y de cuarcita hacen que se levanten sobre el llano algunos pequeños relieves, y la presencia de granitos algo más blandos produce vallejos cerrados.

Los suelos ${ }^{4}$ son ácidos, formados por la descomposición del granito, con gran componente arenoso, poco profundos, pobres en materia orgánica y con poca capacidad de retener la humedad, lo que determina el predominio del bosque de encinas, degradado por la acción antrópica hasta el estado de monte abierto tipo dehesa, y, por tanto, inadecuado, excepto en las orillas de los ríos y en las fuentes, para el cultivo, especialmente el del cereal.

El clima de la comarca de los Arribes ${ }^{5}$, debido a la existencia del cañón formado por el Duero, es de tipo Mediterráneo, contrastando netamente con el de la penillanura, que tiene rasgos de acusada continentalidad, con precipitaciones que oscilan entre los 400 y los $1.000 \mathrm{~mm}$. anuales, incrementándose de Este a Oeste, y diferencias extremas de temperatura. Esto permite que en la comarca de los Arribes tenga una agricultura basada en el cultivo de vides, olivos, cítricos, almendros y otras plantas propias del Levante español, frente a la penillanura, que a penas permite un pobre y escaso cultivo cerealístico y una ganadería extensiva, dedicándose la mayor parte de la superficie a la dehesa de encinas y al monte bajo.

Cabero Dieguez, V.: Cascos Marana, C. y Calonge Cano, G., los Espacios Naturales... 88-92. Cabero Dieguez, V.: Troitino Vinuesa, M A.: Calavia Redondo, M. y Llorente Pinto. J. M., Las Comarcas Tradicionales, vol. VIII de la Geografía de Castilla y León, Valladolid, Ed. Ámbito. 1990, págs. 185-187.

Cabero Dieguez, V., Cascos marana. C. y Calonge Cano, G., Los Espacios Naturales..., págs. 94-96. 


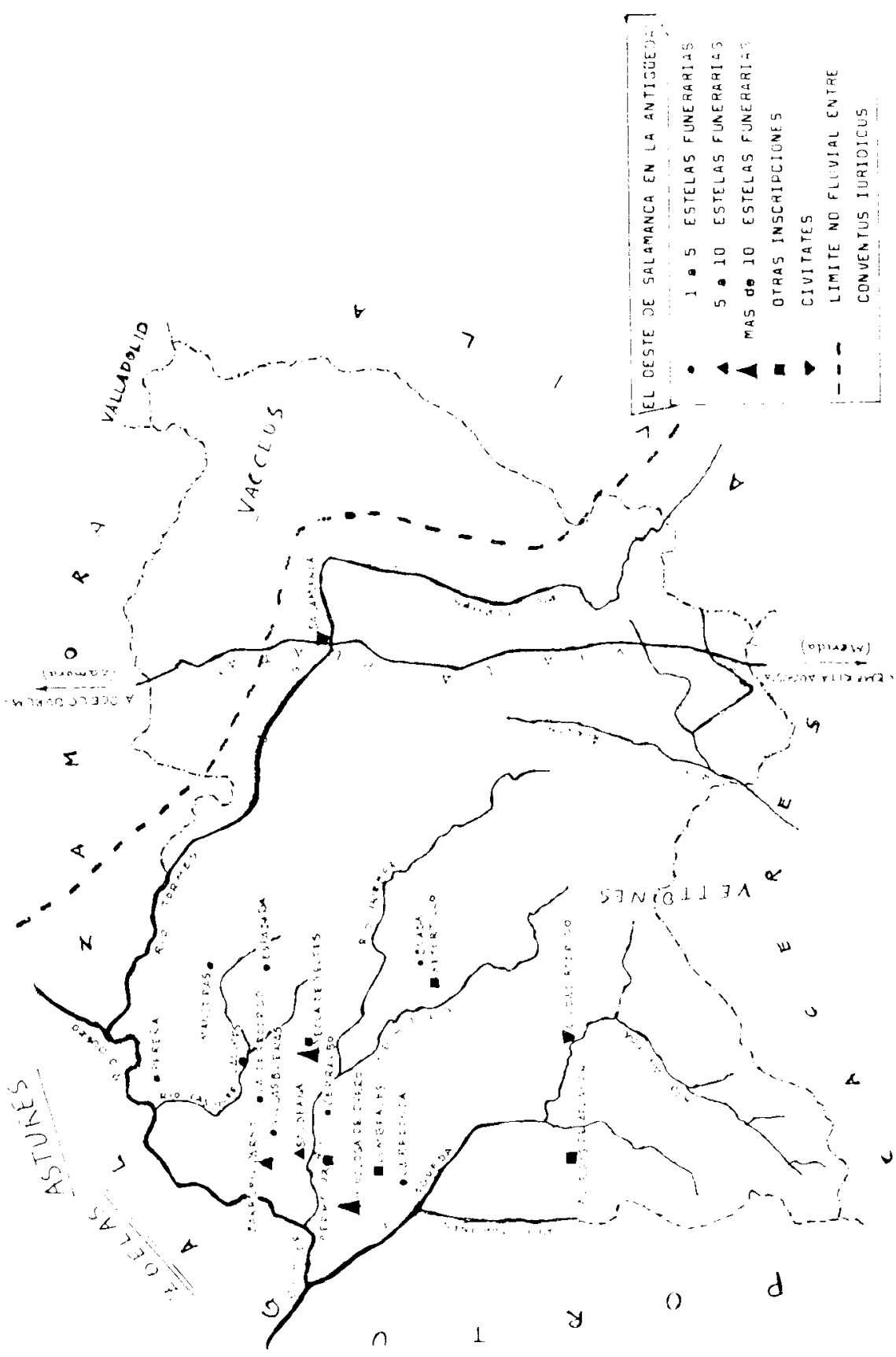


La única riqueza mineral que pudo ser explotada en la antigüedad, además del granito, es el estaño ${ }^{6}$, cuya presencia es reseñada por Plinio ${ }^{7}$.

En la antigüedad, este territorio pertenecía a los Vettones del Conventus Emeritensis ${ }^{\circ}$, a los que el Duero separaba de los Astures del Conventus Asturicensis. En las cercanías de la zona de los Arribes, en la confluencia del Duero con los ríos Sabor y Coa, en territorio portugués, confluian los Conventus Emeritensis, Scallabitanus, Bracaraugustanus y Asturicensis.

\section{CARACTERES EXTERNOS}

Lo primero que llama la atención del conjunto de epígrafes de Medina del Campo es su gran homogeneidad, ya que los 28 epigrafes de la colección son estelas o fragmentos de estelas prismáticas rematadas en cabecera semicircular realizadas en granito gris o rosa, con sendos ejemplos de arenisca y caliza. Estas características son comunes a las del resto de los epigrafes de Hinojosa de Duero. El granito gris y, sobre todo, el rosa son las piedras predominantes en la penillanura del Oeste de Salamanca y especialmente de la zona de los Arribes del Duero.

Las medidas de las estelas también son homogéneas, incluso en su grosor, y podemos concluir que la mayor parte de ellas debieron medir algo más de $1 \mathrm{~m}$ de altura, 0,30 $\mathrm{m}$ de ancho y $0,15 \mathrm{~m}$ de grosor.

El campo epigráfico está formado, en general, por una cartela rectangular excavada en la piedra, con un único caso de Tabula Ansata ${ }^{9}$.

La decoración de la cabecera de estas estelas está formada por ruedas de radios curvos ${ }^{10}$, cuyo número oscila entre 6 y 12 y que son indistintamente levógiros o dextrógiros, rosetas de 5 ó 6 radios rectos ${ }^{11} \mathrm{o}$ una media luna con los cuernos hacia arriba o hacia abajo ${ }^{12}$, y por escuadras de albañil $^{13}$. A veces estos motivos están inscritos en el interior de una hornacina,

Salinas de Frias. M., La Organización Tribal de los Vettones. Salamanca 1986, pág. 44.

PLINIO, NH, 8 XXXIV, 156-157.

"Roldan, J. M. "Fuentes Antiguas para el Estudio de los Vettones", Zephyrus, n." XIX, 1968, págs. 75-76. Salinas de Frias, M., La Organización Tribal..., págs. 21-23.

Ins. n." 27.

P.ej. Ins. n. ${ }^{15} 2,3,6,7,8,9,11,12,13,14,16,17,18,20,22,23,24,26,27,28$.

P.ej. Ins. n. $10,14,15,19,21$

P.ej. Ins. n.: $5,21 \ldots$

P.ej. Ins. n. $6,7,9,15,16,19,20,22,26,27,28 \ldots$ 


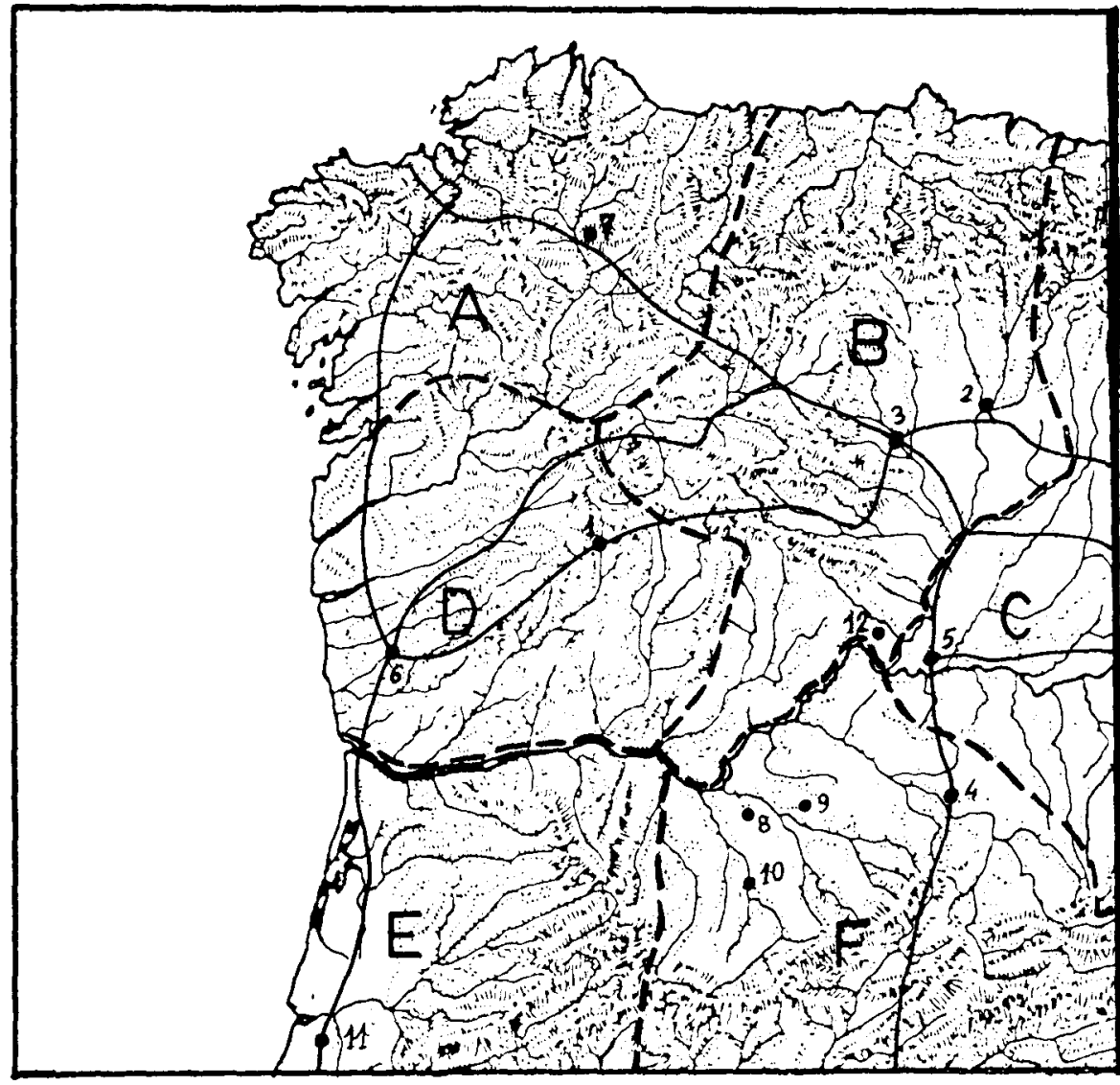

A-Conventus Lucensis

B-Conventus Asturicensis

C. Conventus Cluniensis

D-Conventus Bracaraugustanus

E-Conventus Scallabitanus

F-Conventus Emeritensis
1-Aquae Flaviae

2-Legio

3-Asturica Augusta

4-Salmántica

5-Ocelo Duri

6-Bracara Augusta
7-Lucus Augusti

8-Hinojosa del Duero

9-Yecla de Yeltes

10-Ciudad Rodrigo

11-Conimbriga

12-Villalcampo

formada mediante un listel continuo o una línea simple, también continua, rectangulares o cuadrados rematados en semicírculo ${ }^{14}$. Debajo del campo 
epigráfico, la decoración se reduce, cuando existe, a arquerias ${ }^{15}$. Todos estos motivos son de tipo funerario. Hay pocos casos de estelas bisomas ${ }^{16}$, aunque una es anepigrafa.

Las "ruedas de radios curvos" o las "rosetas de radios rectos" son motivos corrientes dentro de la epigrafia del Norte de Hispania ${ }^{17}$, y es muy común en las estelas salmantinas ${ }^{18}$, en especial en las inscripciones del castro de Yecla de Yeltes ${ }^{19}$. Estos dos motivos son representaciones del astro solar ${ }^{20}$ y también del trueno en la mitología germana ${ }^{21}$.

La «luna» también es un motivo corriente en la decoración de los epígrafes del Norte de la Península ${ }^{22}$, aunque en la región salmantina es extraño ${ }^{23}$ y no está documentado en Yecla de Yeltes. El creciente lunar se interpreta como morada de los muertos ${ }^{24}$.

Las "escuadras de albañil» o «brazos de Atlante» son, asimismo, corrientes en la decoración de los epígrafes del Norte de Hispania ${ }^{25}$, en la provincia de Salamanca ${ }^{26}$ y en las necrópolis de Yecla de Yeltes ${ }^{27}$. Este motivo se relaciona con la Teología Astral, en concreto con las puertas del mundo de los muertos ${ }^{28}$.

Maluquerde Motes, J. Carta Arqueológica... págs. 139-140, n " 124-164. Martin Valls. R. "Inscripción Inédita de Yecla de Yeltes. Salamanca", BSAA, n ": XXXIV-XXXV, 1969. págs. 332-334. Martin Valls, R., "Notas sobre la Epigrafia de Yecla de Yeltes", Durius 1, 1973, págs. 37-43. Martin Valls. R.. "Novedades epigráficas del Castro de Yecla de Yeltes (Salamanca)". Estudios dedicados a Carlos Callejo Serrano. Cáceres 1979, págs. 500-501. MARTIN VAlls. R. "Las necrópolis del Castro de Yecla de Yeltes. Datos arqueológicos para su estudio", Zephyrus, n." XXXIV-XXXV, 1982, págs. 181-191.

:a Marco Simon. F., Las estelas decoradas..., pág. 22. Abasolo. J. A., Albertos, M. L. y Elorza, J. C. Los monumentos funerarios de época romana en forma de casa de la región de Poza de la Sal (Bureba, Burgos). Burgos 1975, pág. 69.

HatT, J. J., "Rota flammis circumsepta. A propos du symbole de la roue dans la religion gauloise", RAE, II, 195†, págs. 82-87

Abasolo, J. A.; Albertos, M. L. y Elorz.A. J. C., Los monumentos funerarios..., págs. 64 67. Marco Simon. F.. Las estelas decoradas..., págs. 19-20.

$\therefore$ NAVASCUES, J. M., "Caracteres externos...", pags. 171.

$\because$ Cumont. F. Recherches sur le symbolisme funéraire des romains. París 1942. págs. 117 y ss. Abasolo, J. A; Albertos M. L. y Elorza, J. C., Los monumentos funerarios... págs. 67 69.

Marco Simon. F.. Las estelas decoradas..., pág. 20

Navascues, J. M. "Caracteres externos ..." pág. 171

Ctr. nota 19

".4 JULLIEN, C., "Chronique Gallo-Romaine. Stèles spagnoles". REA, n."XII, 1910, pág. 89. SHOBEF, A., "Die Römischen Grabsteine von Noricum und Panonien". in Sonderschriften der
} 


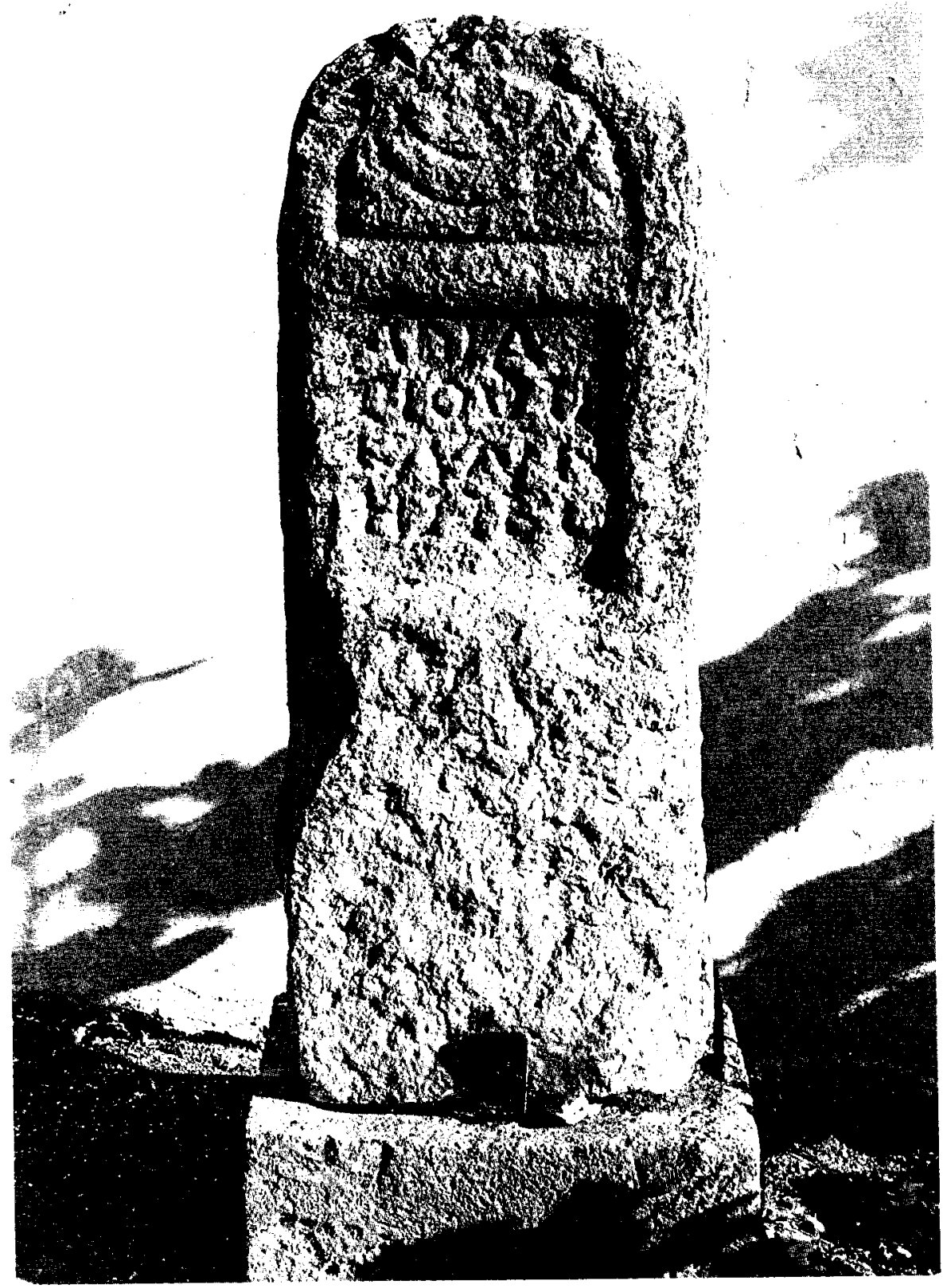

Fig. 1. Insc. n." 5. 


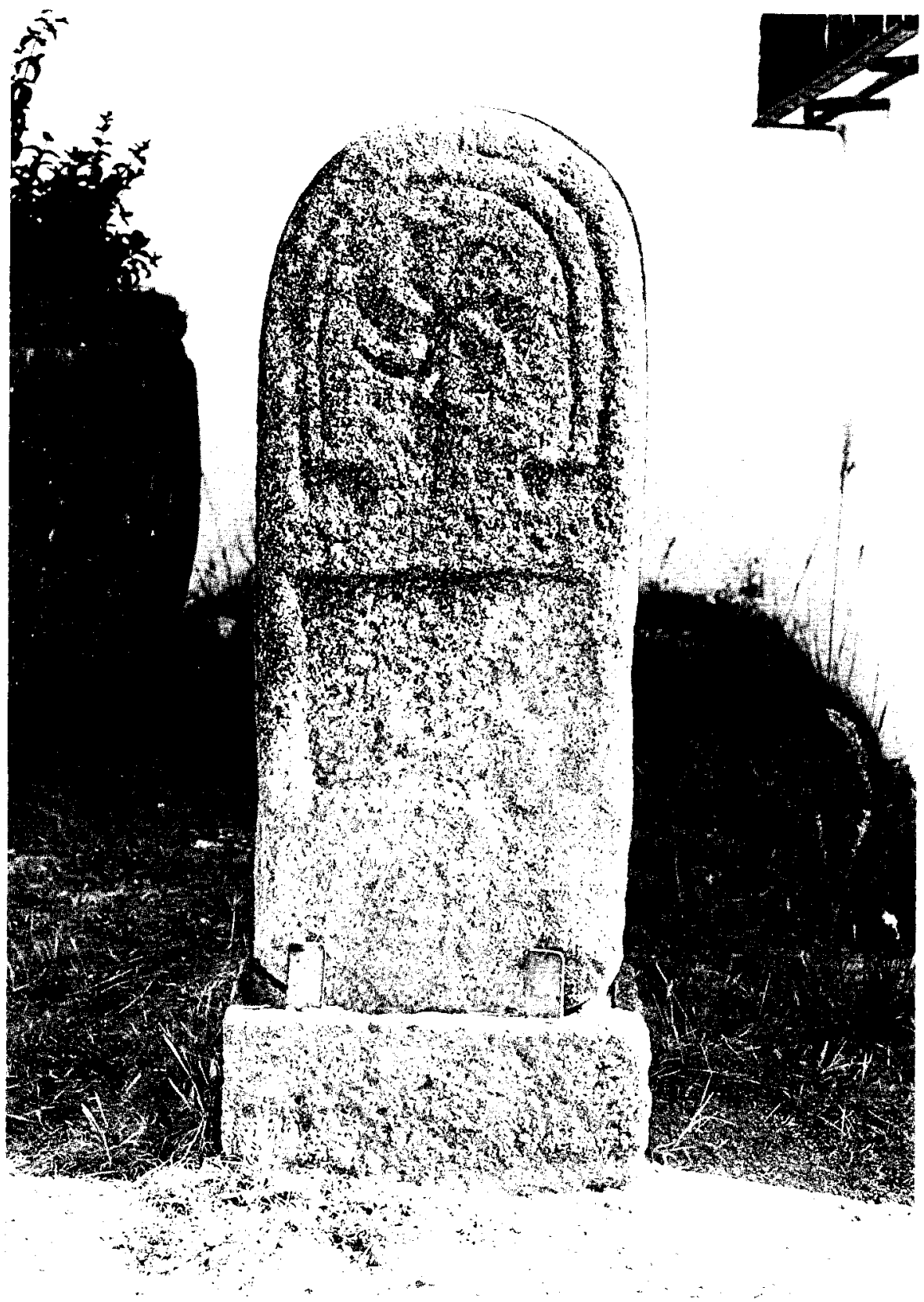

Fig. 2. Insc. n."7 
Las "arquerías" también son motivos corrientes en la decoración de los epígrafes del Norte peninsular ${ }^{29}$, en la región salmantina ${ }^{30}$ y en el castro de Yecla de Yeltes ${ }^{31}$. Este motivo se interpreta, normalmente, como una representación de las puertas del Hades ${ }^{32}$.

Las técnicas empleadas en las estelas de este conjunto son la excavación en la superficie lisa de la piedra para crear un bajorrelieve ${ }^{33}$, y el dibujo de motivos mediante el bisel ${ }^{34}$, lo que es propio de la época Severa $^{35}$.

En conclusión, podemos afirmar que los epígrafes de este conjunto de Hinojosa de Duero, los de Yecla de Yeltes y alrededores ${ }^{36}$ tienen unas características externas muy homogéneas, que contrastan con las de los epígrafes del lado portugués del Duero, habitado por los Zoelas Astures en la antigüedad, separados por el río Duero de los Vettones del Conventus Emeritensis ${ }^{37}$.

A continuación estudiaremos brevemente las características de los epígrafes de esta zona portuguesa y las de los de la limitrofe provincia de Zamora.

Entre el Sabor y el Duero el material utilizado en los epígrafes es mayoritariamente el granito ${ }^{38}$ o la caliza ${ }^{39}$, lo que es normal si se considera la formación geológica del terreno de esta región, ya que no solamente hay granito, sino también rocas del Secundario.

Osterreichischen. Archäelogischen Instituts in Wien, $n .{ }^{\circ} \mathrm{X}, 1923$, págs. 218 y ss. NAGr, L., "Les symbolismes astraux sur les monuments funéraires de la population indigène de la Panonia", Laureae Aquicensis, II, 1941, pág. 238. CumONT, F., Recherches sur le symbolisme..., págs. 232 y ss. Abasolo, J. A. Albertos, M. L. y Elorza, J. C., Los monumentos funerarios..., págs. 70 72.

29 Marco Simon, F., Las estelas decoradas..., págs. 26-28.

30 Navascues, J. M., "Caracteres externos...", pags. 173-174

3t Cfr. nota 19

32 NAGy, L., “Le symbolisme astraux...", pág. 236. Cumont, F., Recherches sur le symbolisme..., págs. 73 y ss. Mangas, J., "Nuevas inscripciones latinas en Salamanca y provincia", AEA, XLIV, 1971, págs. 128-129.

33 Ins. n. 1 a 8,10 y 12 a 25.

${ }^{34}$ Ins. n. ${ }^{a} 9,11,26$ a 28.

${ }_{35}$ BlazQuez, J. M. ${ }^{\text {a }}$, in Austieg und Nüdergen, band 12.2.

${ }_{36}$ Cfr. Maluquer de Motes, J., Carta arqueológica..., págs. 133 y ss. P.ej. Barruecopardo, Saldeana, Villasbuenas, Espadaña, etc.

37 PLINIO, NH. IV, 112.

38 Mourinho, A. M., Epigrafia latina aparecida entre Sabor e Douro desde o fallecimiento do

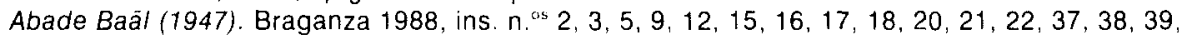
$40,42,44,48,49,50,51,59,65$

39 ldem, ins. n. $4,11,14,23,24,25,27,34,41,43,62,66,67$ 
En la tipología tormal, además de estelas hay cipos ${ }^{40}$ y $\operatorname{aras}^{41}$. La decoración de las lápidas de esta zona de Portugal es más variada que la de la zona occidental salmantina ${ }^{42}$, comprendiendo, escuadras, ruedas de radios curvos, rosetas, esvásticas, cerdos y jabalies y corzos. Especialmente destacan las estelas de cabecera semicircular decoradas con una rueda de radios curvos inscrita en un círculo unido a través de un cuello a una peana situada sobre el campo epigráfico ${ }^{43}$, forma que comúnmente se denomina tipo «Picote», y que está atestiguada en Astor$\mathrm{ga}^{44}$ y en la provincia de Zamora ${ }^{45}$.

En los epígrafes de la provincia de Zamora, especialmente los de Villalcampo y sus alrededores, zona que también fue territorio astur en época romana, se observan diferencias respecto a los de la zona salmantina a la que pertenece este conjunto. Estas diferencias se constatan en los materiales utilizados, que son el mármol, la caliza y el granito ${ }^{46}$. En la decoración, las diferencias se hayan en la presencia del umbo bien marcado en el centro de las ruedas de radios curvos, en la técnica de tallado de las rosetas hexapétalas, en la utilización de la decoración de tipo «Picote», y en la aparición de una estela decorada con los retratos de los difuntos que la encargaron ${ }^{47}$.

También creemos conveniente establecer las diferencias existentes entre este conjunto y la zona a la que pertenece con respecto a los dos núcleos urbanos importantes más cercanos, que son Asturica Augusta y Aquae Flaviae.

En Aquae Flaviae (Chaves) el material en que se realizaron los numerosos epigrafes conservados es mayoritariamente el granito ${ }^{48}$. La decoración de los epígrafes comprende rosetas hexapétalas ${ }^{49}$, trisqueles de

\footnotetext{
Idem, ins. n. ${ }^{\text {is }} 7,8,10,26,28,49$.

44 Mananes PÉrez, T., Epigrafia y numismática de Astorga Romana y su entorno. Salamanca

45. Martin Valls, R. "Epigrafes romanos de Sansueña (Rosinos de Vidriales y Santibánes de Vidriales)", Studia Archaeologica, n." 75, 1975, págs. 15-16. Abasolo, J. A. y Garcia Rozas, R., "Sobre las estelas zamoranas y su ornamentación», Actas del Primer Congreso de Historia de Zamora. Zamora 1990, vol. Il, pág. 546.

46 Abasolo, J. A. y Garcia Rozas, R., "Sobre las estelas zamoranas...", págs. 545-546.

47 Abasolo, J. A. y Garcia Rozas, R., "Sobre las estelas zamoranas...", págs 546-548, láms

is Cfr. Rodriguez Colmenero, A., Aquae Flaviae 1. Fuentes Epigráficas. Chaves 1987.

49 Idem, ins. n." $183,191,539$.
} $1982, n .83$ I-IV. 


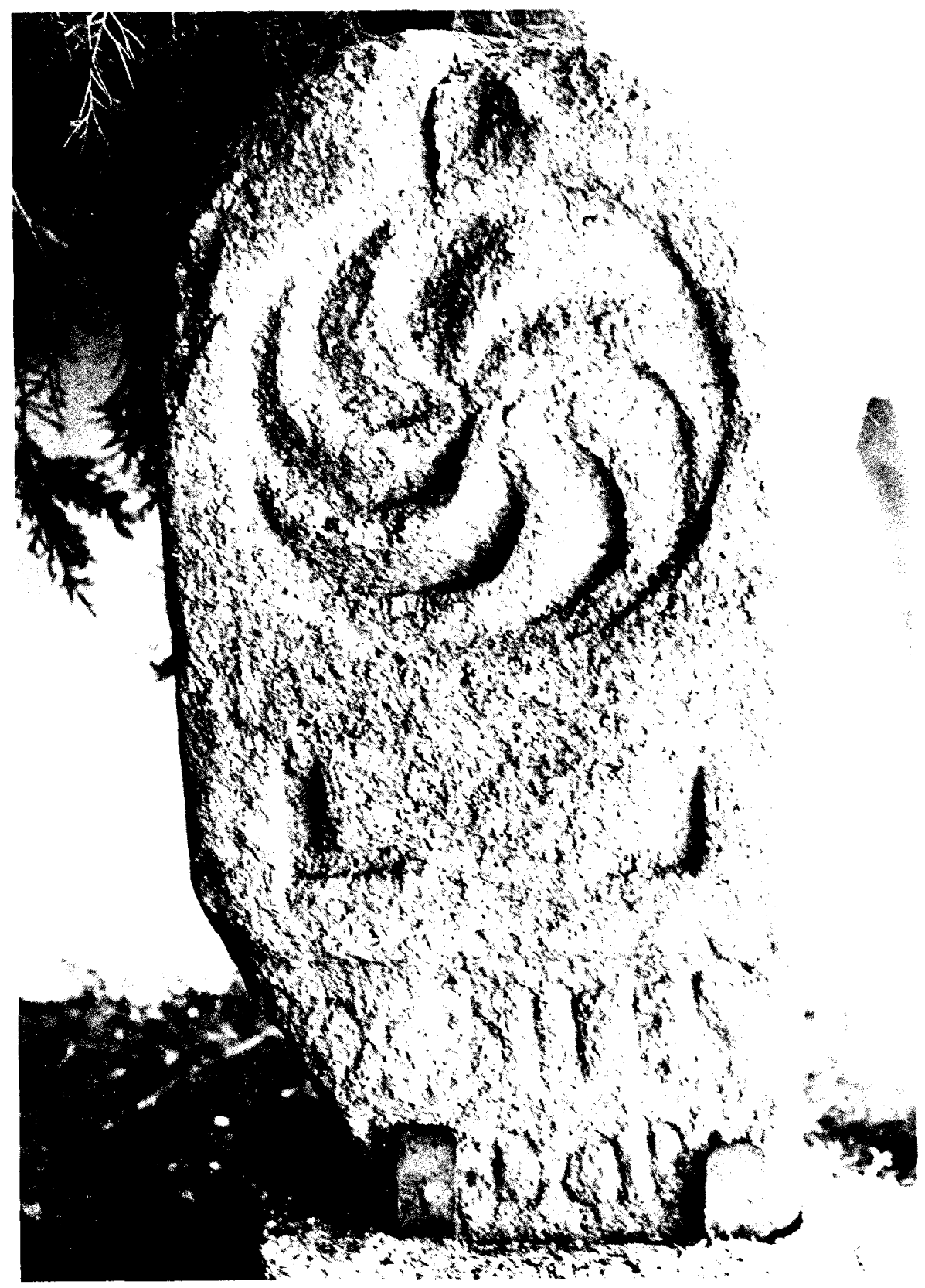

Fig. 3. Insc. n." 9. 
radios curvos ${ }^{50}$, medias lunas ${ }^{51}$, esvásticas de radios curvos ${ }^{52}$, ruedas de radios curvos ${ }^{53}$, figuras humanas ${ }^{54}$, frontones y volutas ${ }^{55}$, arquerías ${ }^{56}$, escuadras $^{57}$ y motivos vegetales ${ }^{58}$. La tipología de los monumentos funerarios comprende placas, estelas, cipos y, sobre todo aras ${ }^{59}$.

En Asturica Augusta (Astorga), capital del Conventus Asturum, los materiales utilizadas en los epigrafes son mayoritariamente el mármol, la pizarra y la caliza ${ }^{60}$. Asimismo, la tipología de los monumentos comprende, estelas, aras y, sobre todo, placas ${ }^{61}$. La decoración de los monumentos es bastante más variada que la de los del occidente salmantino, pues comprende motivos animales, vegetales y astrales, como arquerías, escuadras, medias lunas, ruedas de radios curvos y rosáceas, elementos arquitectónicos, como frontones triangulares, páteras, peltas, esvásticas e incluso armas ${ }^{62}$. Se constata que la rueda de radios curvos, excepto en un solo caso ${ }^{63}$, no aparece nunca en estelas funerarias ${ }^{64}$, lo que contrasta con el conjunto de Hinojosa.

Las inscripciones de este conjunto de Medina del Campo son todas funerarias, como ocurre en el conjunto general de inscripciones del Oeste de Salamanca, lugar en el que sólo hay un Terminus Augustalis en Yecla de Yeltes ${ }^{65}$, un ara dedicada al dios Celiborcae en Villasbuenas ${ }^{66}$, otra dedicada a las Aquis Eletensibus en Retortillo ${ }^{67}$, un ara dedicada a lovi Solutorio en Gallegos de Argañan ${ }^{68}$, un ara dedicada a lovi Optimo Maximo en Bermellar ${ }^{69}$ y una tessera procedente del castro de las Mer-

5o ldem, ins. n. ${ }^{\circ} 184$

Idem, ins. n. ${ }^{\text {os }} 184$ y 191

ldem, ins. n. os $182,187$.

ldem, ins. n. ${ }^{\text {os }} 202,207,211$

ldem, ins. n. $196,200,218$

Idem, ins. n. ${ }^{\text {os }} 22,59,73,88,110,181,535$.

ldem, ins. n. os $186,191,539$.

loem, ins. n. 191.

lom, ins n. 184.

Cfr. Rodriguez Colmenero, A., Aquae Flaviae.

Mananes Pérez, T., Epigrafía y numismática..., págs. 147-148.

ldem, págs. 148-152.

ldem, págs. 153-155

ldem, ins. n. 34 .

ldem, pág. 158.

55 Maluduer de Motes, J., Carta arqueológica..., n. 165

66 lodem, ins n. ${ }^{\circ} 122$.

67 ldem, ins n. ${ }^{\circ} 91$.

68 Idem, ins. $n .^{\circ}$ 37. La inscripción está realizada por Vitullus Arreini f(ilius), un indigena romanizado.

69 Idem, ins. n. ${ }^{\circ}$. Este ara fue levantada por Egma(tius) Pat(ernus) -la lectura puede ser Eg<n>atius y Pat(erni) $F$ (ilius) - con lo que tendriamos un individuo mucho más romanizado que el de la inscripción anterior, lo que también parece indicar el hecho de invocar a Júpiter Optimo Máximo y no a un sincretismo entre Júpiter y una deidad indígena. 
chanas en Lumbrales ${ }^{70}$. Frente a esta característica, en el territorio portugués hay varias inscripciones honorarias y votivas ${ }^{71}$, incluyendo dos inscripciones dedicadas a Júpiter Óptimo Máximo ${ }^{72}$, una de ellas encargada por un ordo civium romanorum; en Astorga ocurre algo similar ${ }^{73}$ y en Chaves las inscripciones votivas predominan sobre las demás, incluidas las funerarias ${ }^{74}$.

\section{CARACTERES INTERNOS}

Los textos de las inscripciones de este conjunto son muy breves, desarrollándose en 4 ó 5 líneas, lo que es común a toda la epigrafía del Oeste de Salamanca ${ }^{75}$.

La ordinatio de las inscripciones de este conjunto es correcta, ya que las letras se adaptan perfectamente al espacio destinado en las lápidas al campo epigráfico, que normalmente es una cartela rectangular ${ }^{76}$. En ninguna inscripción se aprecian líneas-guias.

Las letras de las inscripciones son capitales rústicas. Como caracteres paleográficos destacan las $\mathrm{M}$ y las $\mathrm{N}$ muy abiertas, las $\mathrm{A}$ sin travesaño y la $E$ arcaica, trazada mediante dos trazos paralelos $(I=E)$. Estos caracteres coinciden perfectamente con los del resto de la epigrafia del occidente salmantino ${ }^{77}$.

La puntuación se realiza mediante simples puntos de sección circular, que separan palabras.

Los formularios empleados en las inscripciones son el encabezamiento $D M, D M M \circ D M S$, y la utilización de la fórmula funeraria final de manera abreviada $H S T T L$, lo que también es una pecualiaridad corriente en los epitafios del Oeste salmantino ${ }^{78}$; esta fórmula sólo se emplea completa - H S E S T T L- en dos inscripciones ${ }^{79}$. La expresión de la edad adopta normalmente la abreviatura AN, documentándose sólo

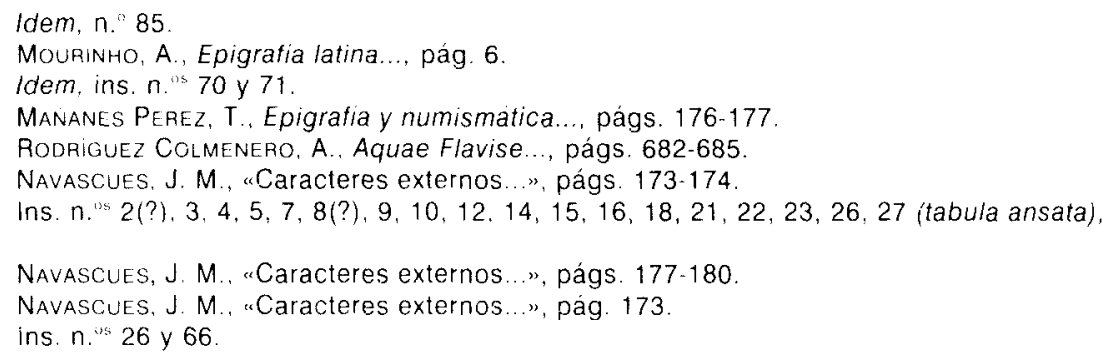




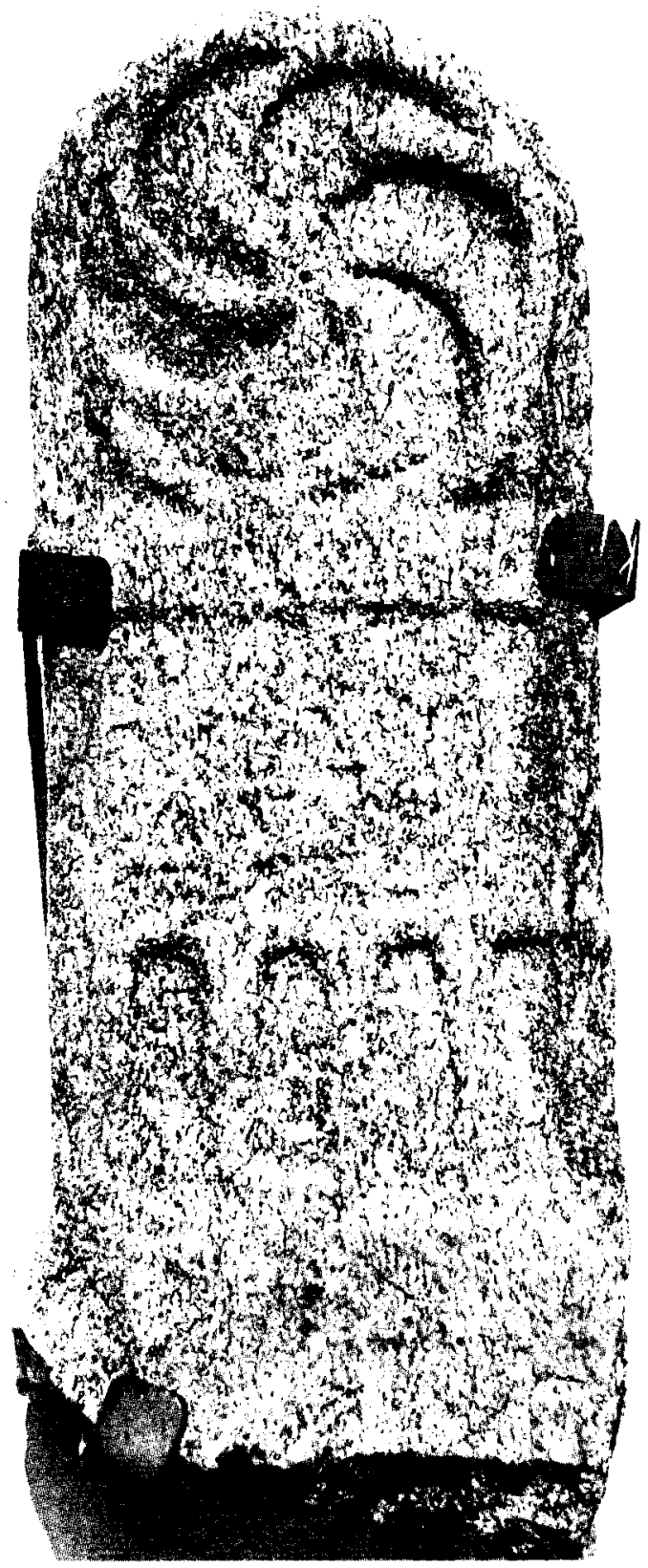

Fig. 4. Insc. n. 11. 
en unos pocos casos la abreviatura $A N N^{80}$. La edad viene expresada normalmente mediante múltiplos de $X \circ \mathrm{V}$.

La formación del nombre es muy simple, ya que consiste en el nombre seguido por su filiación, con pocos casos en los que sólo se exprese el nombre ${ }^{81}$, y otros dos en los que aparece un nombre con dos elementos -nomen y cognomen- ${ }^{82}$. Estos sistemas onomásticos responden, respectivamente, al primer - nomen o nomen y filiación - y al segundo - nomen y cognomen - sistema descrito por Navascués para las inscripciones salmantinas ${ }^{83}$, que considera que el primero es típicamente indígena y el segundo es un compromiso entre lo indígena y la formación romana del nombre. También hay un ejemplo de tria nomina ${ }^{84}$.

La onomástica del conjunto de Hinojosa de Duero es mayoritariamente indígena. Los nombres romanos, si se exceptúan Avitus y Attius que ocultan un nomen indigena homófono a un latino, se reducen, a Divilius, ... us Caii f., Attius Aquilus, Alia Paterna, Celsidius Caii. f., Iunius Aviti f., Domitio, Flavia Flavii f., Avita Opii f., Lucius, Severus, Placidus, Proculus, Modestinus, Lupercus, Ovinia, Albus, Lucius Accius Caeno, Silo Valerii f., Modestinus Modesti f., Fronto Silonis $f$. y Clemens. Este predominio de los nombres indígenas sobre los latinos es normal en la epigrafía salmantina ${ }^{85}$, lo que contrasta con la epigrafía de la zona portuguesa comprendida entre el Sabor y Duero, en la que hay muchos más nombres latinos ${ }^{86}$. Sin embargo, en la provincia de Zamora predominan los nombres indígenas sobre los latinos ${ }^{87}$.

Este predominio de la onomástica indigena en Zamora y Salamanca marca una clara diferencia con lo que ocurre en Aquae Flaviae, en la que los nombres latinos predominan sobre los autóctonos e incluso se documentan cognomina griegos ${ }^{88}$, y con lo que se observa en Asturica Au-

Ins. n. $8,18,28,32,33,50,64$

Ins. n." $8,17,44,45,47$

Ins. n. $26,29$.

8.3 Navascues, J. M., "Onomástica salmantina de Época Romana", BRAH, n." CLVIII, 1966, pàgs. 191-194.

84 Ins. n." 50 .

h. Cir. Maluquer de Motes, J., Carta Arqueológica..., págs. 143-145. Navascues, J. M., "Onomástica salmantina...", págs.1898 y SS. MANGAS, J., "Nuevas inscripciones Latinas de Salamanca y Provincia”, AEA, XLIV, 1071, págs. 127-136. MARtín VALLS, R., "Novedades epigráficas...", págs. 500-501. Martin VALLS, R.. "Inscripción Funeraria... págs. 332-334. Martin VaLLS, R., "Notas sobre la Epigrafía..." págs. 37-43. Martin Valls, R., "Las necrópolis del Castro...", págs. 181-191

ati Moufinho, A. M., Epigrafia latina..., págs. 132

Cfr. notas 46 y 47

hy Rodriguez Colmenero. A., Aquae Flaviae..., págs. 710-713 
gusta, ciudad en la que también predomina la onomástica latina sobre la indigena $y$ en la que también se constatan nombres griegos ${ }^{89}$, siendo corrientes en ambas ciudades los tria nomina, de los que se documenta pocos casos en los epigrafes del Oeste salmantino ${ }^{90}$. Es decir, constatamos que, en dos ciudades importantes, una de ellas municipio, hay un predominio del nombre latino sobre el indígena, a diferencia de núcleos rurales, en donde el nombre indígena domina sobre el latino.

La composición de la sociedad, que aparece en estos epígrafes, de Hinojosa, está formada por hombres libres -peregrini-, ya que no aparecen ni esclavos, ni libertos ni ninguna clase de magistrados ni de profesiones. La presencia de nombres latinos, junto con la realización de estas estelas, sólo indica que está en marcha el proceso de romanización, aunque no podemos decir si en Hinojosa de Duero hay o no ciudadanos romanos.

La cronología de las inscripciones de Hinojosa de Duero abarca desde el siglo \|d.C. hasta la época Severa, conclusión a la que se llega a través de los caracteres decorativos de las estelas, de la paleografía de las letras y del uso de las fórmulas funerarias. Estas fechas coinciden con la dadas para las inscripciones de la provincia de Salamanca ${ }^{91}$.

\section{TALLER}

Las características reseñadas para este conjunto epigráfico, que son comunes con el resto de las inscripciones del Oeste de Salamanca, permite afirmar la existencia de un taller epigráfico en esta zona. Este taller está especializado en la fabricación de estelas que mayoritariamente son funerarias. Su repertorio decorativo es bastante reducido, ya que comprende una serie de motivos astrales, como ruedas de radios curvos, rosetas, escuadras, crecientes lunares, hornacinas realizadas mediante molduras y simples círculos incisos, motivos de tipo arquitectónico, como arquerías y otros motivos, como aspas.

Las estelas tienen un orden compositivo uniforme, ya que comprende una cabecera, cuya decoración se realiza con los motivos astrales reseñados, el campo epigráfico, formado normalmente por una cartela rec-

\footnotetext{
Mananes Pérez, T., Epigrafia y numismática..., págs. 180-184.

Cfr. notas $19,36,83$ y 85.

Navascues, J. M., "Caracteres externos...". pág. 186. Mangas, J., "Nuevas inscripciones...", págs. 127-136. MARTIN VAlLS, R., "Notas sobre la epigrafía romana...", pag. 43
} 


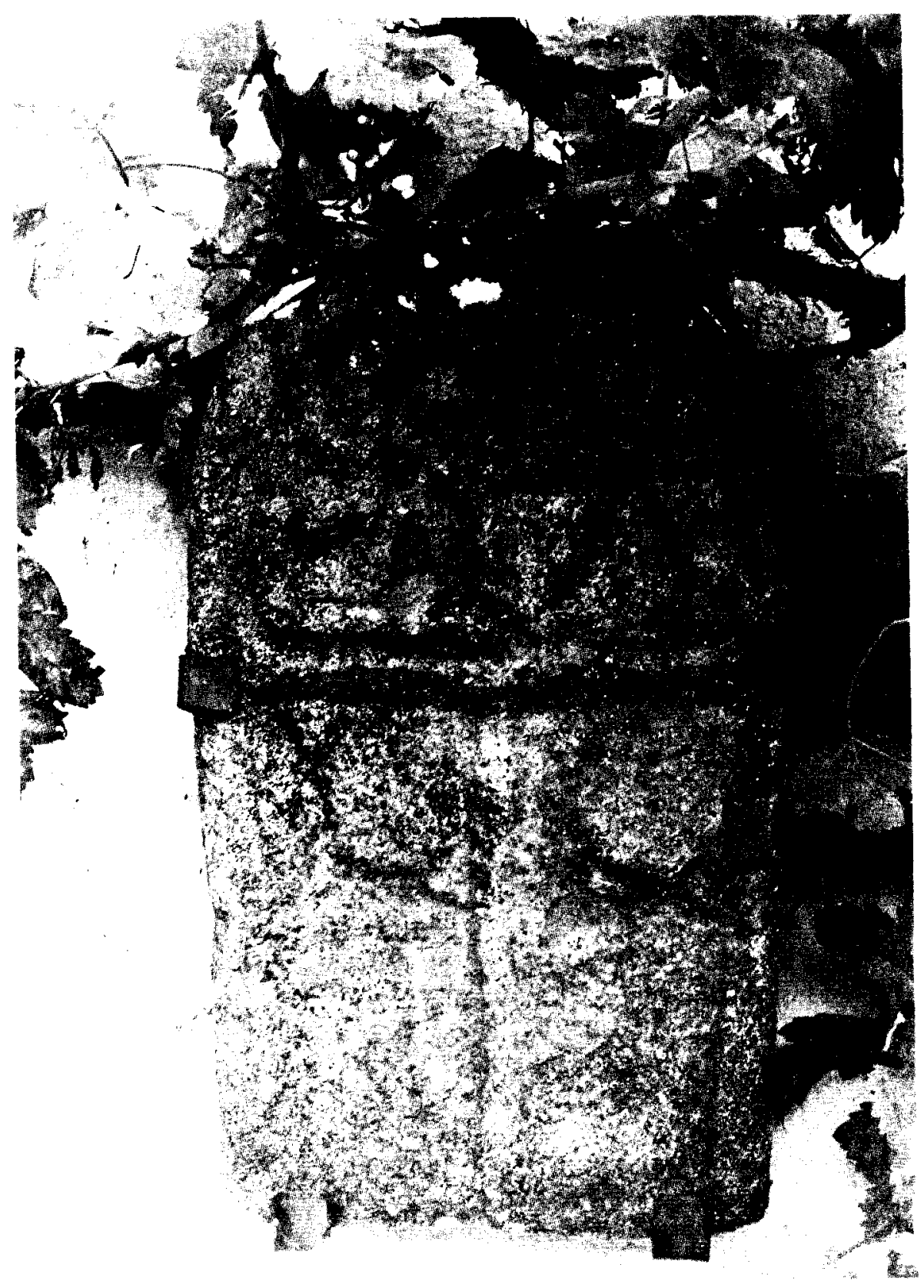

Fig. 5. InSC. n." 14. 


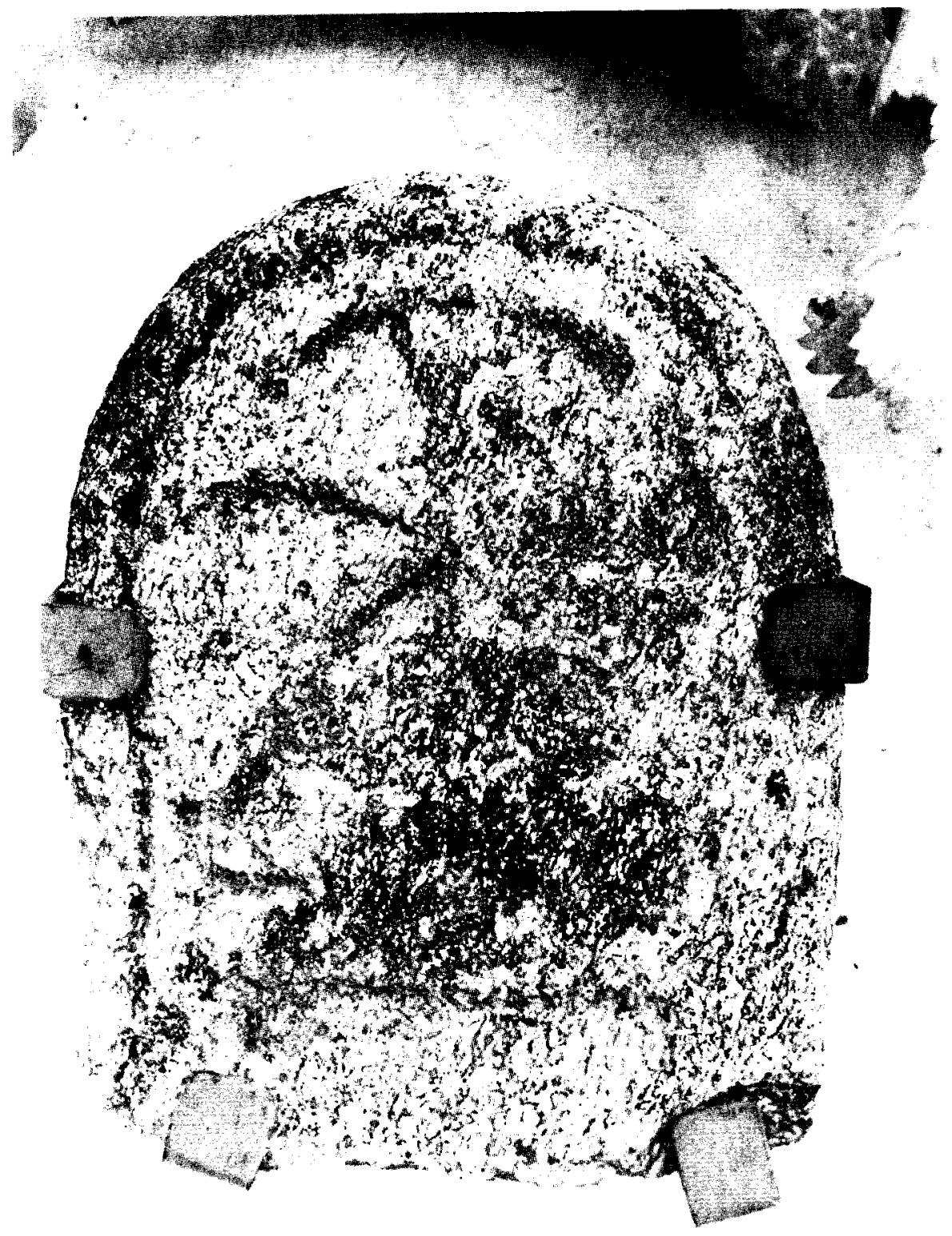

Fig. 6. Insc. 17. 15 
tangular rehundida, y un registro inferior que puede estar decorado con arquerías o con un aspa, o no tener ninguna clase de decoración.

Los textos son breves, nunca superiores a seis líneas, y el formulario utilizado es, normalmente, el nombre del difunto con su filiación seguido por su edad.

Este taller tiene unas particularidades paleográficas características, como la conservación de la $\mathrm{E}$ arcaica, las $\mathrm{A} \sin$ travesaño y las $\mathrm{M}$ y $\mathrm{N}$ muy abiertas. Asimismo, tiene como peculiaridades la abreviación de la fórmula funeraria final en $\mathrm{HST}$ S L, y el predominio de la abrevitura AN sobre ANN para expresar la edad.

Su periodo de funcionamiento comprende desde, muy posiblemente, la segunda mitad del siglo II d.C., hasta la época Severa, observándose una cierta evolución en las técnicas empleadas, que pasan desde la simple excavación en la piedra, hasta el empleo de la técnica del bisel.

\section{CONCLUSIONES}

En resumen, estamos en presencia de un taller de tipo local, enclavado en un medio rural, provinciano -sermo ruralis - ${ }^{92}$, habitado mayoritariamente por indígenas poco romanizados, como demuestra la onomástica de las inscripciones. Su especialización, su parquedad de motivos decorativos y su escasa evolución encajan perfectamente con el aislamiento en la época antigua de la comarca que ocupan, alejada de las vías de comunicación, ya que la vía de la Plata pasa por el Este de Salamanca y las vias de Asturica hacia Gallaecia y el Oeste de la Lusitania discurren

\footnotetext{
9: Cicerón. Ad. Fam. IX. 21: Verum tamen quid tibi ego videor in epistolis? Nome plebeio sermone agere tecum? Cicerón llama sermo plebeius al modo de hablar del pueblo llano, que es más sencillo que el lenguaje de la nobilitas a la que él pertenecia, y asi diferencia dos estilos de hablar de lengua latina. De la misma manera Bandinelli-BIANChI, R., "Arte Plebeyo", Sautuola. I. XIV, 1975, págs. 189-197, trad. del italiano por A. Balil) llama arte plebeyo a toda forma de arte que no pertenezca al arte aúlico oficiai, que es encargado bien por los poderes públicos. el emperador, o por los miembros de la nobilitas imperial De esta forma, entendemos que el arte realizado por los indigenas de la Meseta Norte, muy influenciado por el arte romano. merece el calificativo de sermo ruralis de la misma manera que al arte que se produce en los campa. mentos militares, en el que se observa una simplificación respecto al arte oficial e incluso respecto al arte romano-provincial. se le llama sermo rusticus, ya que se produce fuera de las zonas en las que se realizan las obras del arte oficial -..sermo patricius - y de ese arte de las provincias, que es un derivado del arte ... sermo plebeius -. y que merece el calificativo de sermo urbanus, ya que se produce en la ciudad o en la villa.

Para conocer la aplicación en Hispania de estas formas de expresión artística, vide BaLIL. A.. "Sull'arte della Peninsula Iberica in età romana", Colloquio Italo Spagnolo sul Tema: Hispania Romana (Roma, 15-16 maggio 1972). Roma 1974, pags. $47-64$ y figs
} 


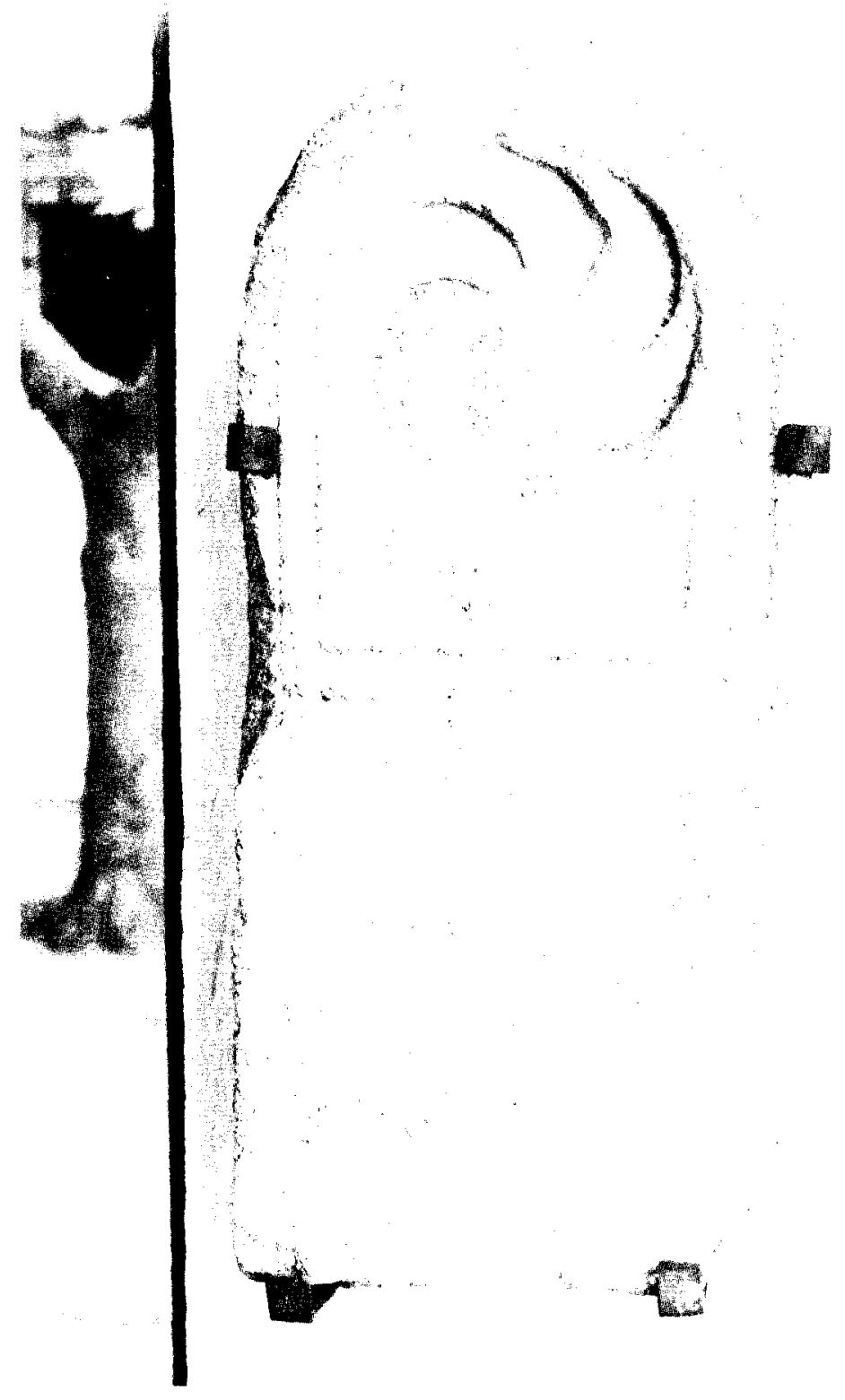

Fig. 7. Insc. n." 26. 
por el lado portugués de la frontera, netamente separada por el cañón formado por el Duero. Además, los centros urbanos importantes, como Asturica Augusta, Clunia, Aquae Flaviae, Bracara Augusta, Scallabis, Olissipo, Conimbriga o Emerita Augusta, capital del Conventus al que pertenece esta comarca, están muy alejados entre sí, así como los centros más romanizados de la provincia como los de Salamanca, la antigua Sal. mantica, y Ciudad Rodrigo, en los que también se observan numerosas perduraciones del mundo indigena.

Sin embargo, la existencia de este taller, con todo su localismo, es una prueba de romanización, que permite afirmar que, al menos desde mediados del siglo ॥ d.C., los Vettones que habitaban a orillas del Duero entre los valles del Tormes y el Huebra podian permitirse el lujo de costear estelas funerarias realizadas bajo una concepción funeraria de tipo romano - motivos decorativos, utilización de las fórmulas funerarias $D M, D M S$ o D M M y H T T L-, aunque fuesen realizadas por un taller local.

Las estelas están realacionadas con importantes castros, lo que está plenamente demostrado para el castro de Yecla la Vieja en Yecla de Yeltes ${ }^{3.3}$ y que habría que comprobar para el caso de la Cabeza de San Pedro en Hinojosa de Duero. La concentración de las estelas en esta zona tiene que ver con sus mayores posibilidades agricolas, que contrastan con la pobreza general del resto de la penillanura, que en la antigüedad se dedicó principalmente a la ganadería ${ }^{94}$.

\section{CORPVS DE INSCRIPCIONES DE HINOJOSA DE DUERO}

1. Anepigrafa.

2. Anepígrafa.

3. Anepigrafa.

4. ANDIIR/I[I]N(US) TR/ITI.F(ilius).AN(norum) / XV M(onumentum),

5. ADIA CLOVTI F(ilia) AN (norum) LX / H(ic) $S$ (ita) $T$ (ibi) T(erra) L(evis).

6. D(iis) M(anibus) / ANIV(s) / DOVITERO / [H(ic) S(itus)]T(ibi) [T(erra) L(evis)].

"3. Mariin Valls. R.. "Las necrópolis...", pags. 181-191. Navascues, J. M., "Caracteres externos...». págs. 163-165.

Salinas de Frias. M. La organización tribal..., pág. 44. 
7. $\mathrm{D}$ (iis) $\mathrm{M}$ (anibus) $\mathrm{S}$ (acrum) /...

8. $\mathrm{D}$ (iis) $\mathrm{M}$ (anibus) / AMA / ANN(orum) XX/[H(ic) ] S(ita)T(ibi) T(erra) L(evis).

9. DOBITER/[en o in]A.DOBIT[eri / F(ilia) AN(norum) ?? / [H(ic) S(ita) $T$ (ibi) T(erra) L(evis)].

10. D[oid]ERA [Ma]/GILONIS / F(ilia).AN (norum).L./ H(ic) S(ita) T(ibi) $T$ (erra) L(evis).

11. AMBATVS / DIV $<\mathrm{I}>\mathrm{LI}$ (i) $\mathrm{F}$ (ilius) / AN(norum)XXV / H(ic) S(itus) $\mathrm{T}$ (ibi) $\mathrm{T}$ (erra) L(evis).

12. Anepigrafa.

13. Anepigrafa.

14. Anepigrafa.

15. $\mathrm{D}$ (iis) $\mathrm{M}$ (anibus) / ...

16. $\mathrm{D}$ (iis) $M$ (anibus) / AVITV[s] / AVITI.F(ilius) / AN(norum) $X X X /[H$ (ic) $S$ (itus) $T$ (ibi) $T$ (erra) L(evis)].

17. $D$ (iis) $M$ (anibus) / ILOS... / AN(norum) $X /[H$ (ic) $S$ (itus) $T$ (ibi) T(erra) L(evis)].

18. $\mathrm{D}$ (iis) $\mathrm{M}$ (anibus) $M$ (onumentum) / REIBVRRO $E \ldots / \ldots$... ANN(orum).../ [H(ic) S(itus) $T$ (ibi) $T$ (erra) L(evis)].

19. Anepígrafa.

20. Anepígrafa.

21. $D$ (iis) $M$ (anibus) $M$ (onumentum) /ANA $[\ldots] / \ldots$

22. Anepígrafa.

23. $\mathrm{D}$ (iis) $\mathrm{M}$ (anibus) $\mathrm{M}$ (onumentum) / AMA [... $/ . . / \mathrm{H}$ (ic ) $] \mathrm{S}$ (ita) $\mathrm{T}$ (ibi) $T$ (erra) L(evis).

24. $\mathrm{D}$ (iis) $\mathrm{M}$ (anibus) / DO[vit(erus)] / AN(norum) $X /[\mathrm{H}$ (ic) $\mathrm{S}$ (itus) $\mathrm{T}$ (ibi) $\mathrm{T}$ (erra) L(evis)].

25. ...NS.CAI// F(ilius) AN (norum) / XXX /H(ic) $S$ (itus ) $S$ (it) $T$ (ibi) $T$ (erra) L(evis).

26. $\mathrm{D}$ (iis) M(anibus) S(acrum) / ATTIVS.AQ/VILVS.AN(norum )/ XXXV.H(ic).S(itus)/E(st) S(it) T(ibi). T(erra ). L(evis).

27. $\mathrm{D}$ (iis) $\mathrm{M}$ (anibus) / REBVRRI/NOREBV/ $\angle \mathrm{R}>\mathrm{RI} F$ (ilio) $\mathrm{AN}$ (norum) XX/II. H(ic). S(itus).T(ibi).T(erra).L(evis). 


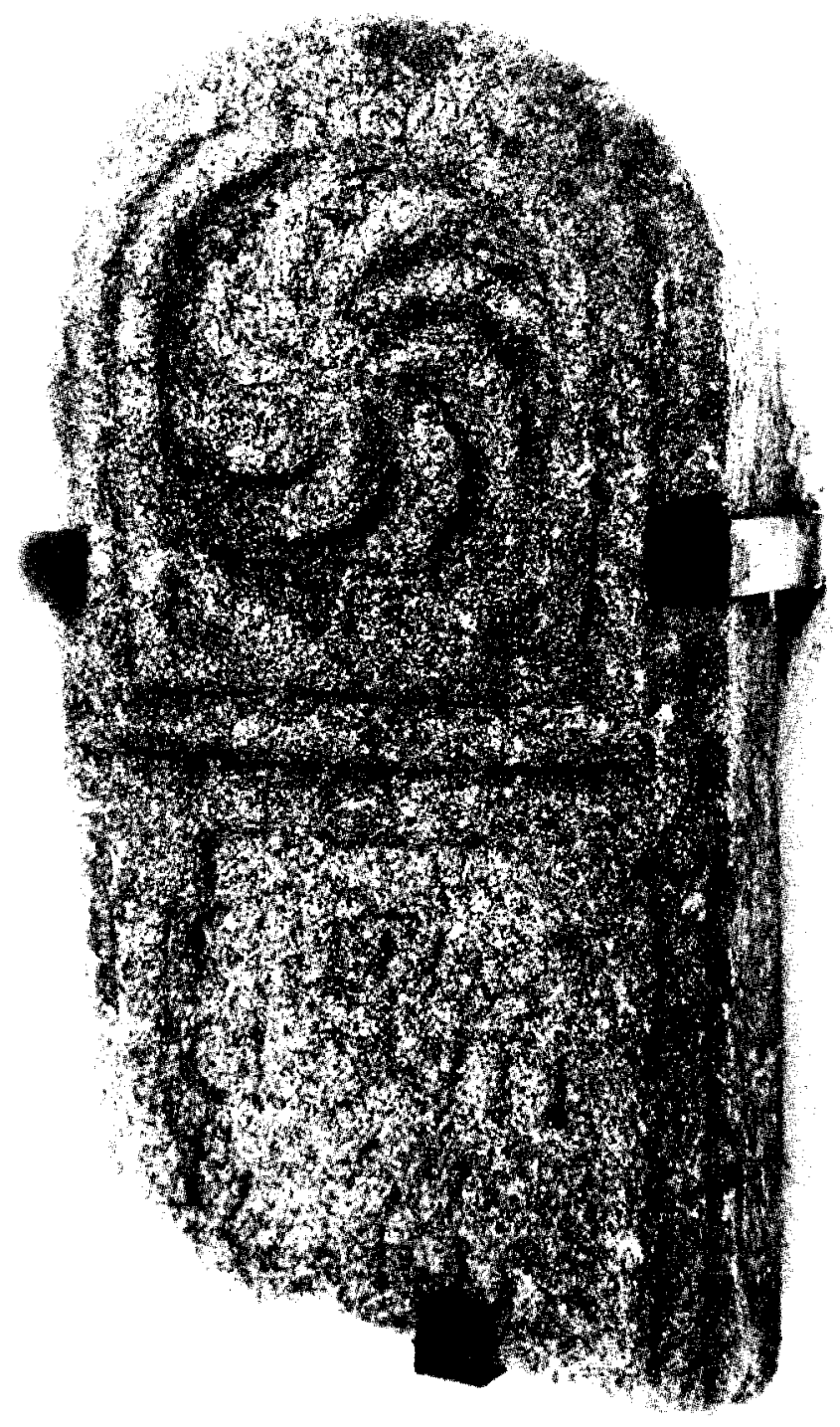

Fig. 8. Insc. n. 28. 
28. CIILTIVS / CLOVTI (i) / F(ilius) ANN(orum) X/XXII H(ic) S(itus) S(it) $\mathrm{T}$ (erra) L(evis).

29. (M.38) ALIA / PATERN/A ANN/ORVM / XXXV $8 \mathrm{~S}$ (it) T(ibi) T(erra) L(evis).

30. (M.39) CELSI[DIV]/S CAl(i) F(ilius) AN(norum) $/ \ldots / H$ (ic) $E$ (st) T(ibi) / T(erra) L(evis).

31. (M.40) CLOVT/I(a) AM/BATI F/ILIA $[\mathrm{A} / \mathrm{N}$ (norum)]...

32. (M.41) D(iis) M(anibus) S(acrum) /IVNIVS / AVITI/FILIVS / ANN(orum) III/ HIC T(ibi) T(erra) L(evis).

33. (M. 42) DOBITEI/NA AVLO/NI F(ILIA) / ANN(ORUM) XV/H(ic) S(ita) T(ibi) T(erra) L(evis).

34. (M.43) DOMITIO / BASSINI $\angle F(I L I O)>/ A N($ norum).L.H(ic) S(itus) / S(it) T(ibi) T(erra) L(evis).

35. (M.44) D(iis) M(anibus) S(acrum) / CAESUL/LA CASSI /F(ilia) AN(orum) XV/ ...

36. (M.45) D(iis) M(anibus) S(acrum) /FLAVI(a) / FLAVI(i) F[il]/IA $\mathrm{AN}$ (norum) XXV / H(ic) $S$ (ita) $S$ (it) ...

37. (M.46) D(iis) M(anibus) $S$ (acrum) / AVITA OP(ii) \& F(ilia) - / $A N<N=O$ (rum) $X L V / H$ (ic) $S$ (ita) S(it) T(ibi) T(erra) L(evis).

38. (M.47) D(iis) M(anibus) S(acrum) / ESTINS SE/AP(i) F(ilius) AN (norum) $V / H$ (ic) $S$ (itus) $T$ (erra) $L$ (evis).

39. (M.48) DOVITE/INA SA E LCI F(ili a) $A N($ orum) / XXX... H(ic) $S$ (ita) $S$ (it) $[T$ (ibi) $T$ (erra)] L(evis).

40. (M.49 ab) LABOI/NA ALAIS <F(ilia) > A/N(norum) LV/ $H$ (ic)S(ita) $T$ (ibi) T(erra) L(evis).

AVRE/LI(us) V/VCI [F(ilius) / AN(norum)] / L H(ic) S(itus) S(it) T(ibi) T(erra) L(evis).

41. (M.50) LAPO/NA LVCl(i) F(ilia) A/N N O (r urn) /XII H(ic) S(ita) / $E$ (st) $T$ (ıbi) $T$ (erra) L(evis).

42. (M.51) MAELA /SEVERI/F(ilia) AN(norum) XXN H(ic) $S$ (ita) $T$ (ibi) T(erra) L(evis).

43. (M.52) ...PLACIDI F(ilius ?) / AN(norum) LV/D(iis) M(anibus) $\mathrm{S}$ (acrum).

44. (M.53) D(iis) M(anibus) S(acrum) /PROC V LVS / AN (norum)...

45. (M.54) D(iis) M(anibus)S(acrum) / MODES/TINVS / AN(norum) L. 


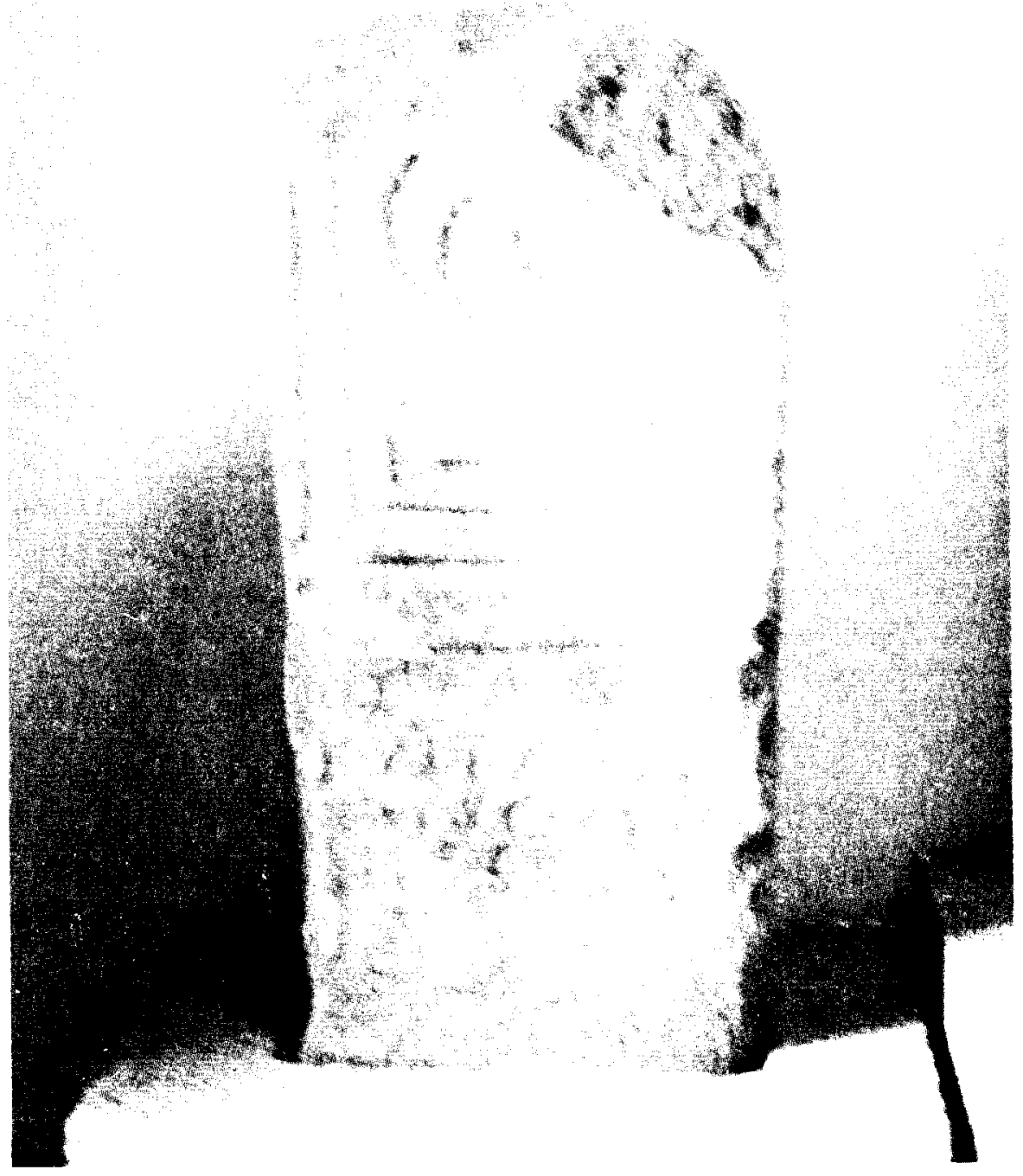

Fig. 9. Insc. ก. 37 
46. (M.55) MVN[IMENTVM] /LVPERC (vs)/ TVRAI F(ilius).

47. (M.56) OVINI/A AN(norum) XV H(ic)S(ita) S(it) / T(ibi) T(erra) L(evis).

48. (M.57) RVSVS / ALBI F(ilius) / AN(norum) ...

49. (M.58) TANGIN/O TR[ITI(i)] F(ilio) /AN(norum) ...

50. (M.59) L(ucius) ACCIU/S CAEN/O ANN(orum) L / H(ic)S(itus) S(it) T(ibi) T(erra) L(evis).

51. (M.60) LAPOE/NA CA/ENON/IS <F(ilia)> AN(norum) / XXV...

52. (M.61 ab)D(iis) M(anibus) S(acrum) / PLAC/IDVS / RE(bvrri) $<F$ (ilius) > AN(norum) / VII HI(c).

$D$ (iis) $M$ (anibus) [S(acrum)] / REBV/R $<\mathrm{R}>\mathrm{R}<\mathrm{N}>/ \mathrm{RE}$ (burri) $\mathrm{F}$ (ilia) / $A N$ (norum) V / H(ic) T(erra) L(evis).

53. (M.62) MEDVS/INVS... ADR/I $F$ (llius) $A / N<N>O$ (rum) $X X / H$ (ic) $E$ (st) $S$ (it) $T$ (ibi) T(erra) L(evis).

54. (M.63) D(iis) M(anibus) / MODIVS MO(dii) F(ilius) /[AN (norum)]...

55. (M.64) DI(is) MA(nibus) / S(acrum) S(extus ?)VALE/RI (i) $<F$ (ilius) $>A$ (nnorum) XXI.

56. (M.65) MODESTI/NVS MOD/ESTI F(ilius) AN(norum) / XLV H(ic) S(itus) $E$ (st) / S(it) T(ibi) T(erra) L(evis) .

57. (M.66) D(iis) M(anibus) / IANVA / AN(norum)...[H(ic)]/S(ita) T(ibi) T(erra) L(evis).

58. (M.67) CLOVTIVS / DOVITERI /F(ilius) AN(norum) LXV / S(it) T(ibi) T(erra) L(evis).

59. (M.68) FRONTO / SILONIS/ F(ilio) AN $<N>O$ [RUM] XX / HIC S(itus) / $\mathrm{E}$ (st) T(ibi) T(erra) L(evis).

60. (M.69) APANA / BOVTI/ F(ilia) $\mathrm{AN}$ (norum) $>\mathrm{XXH}$ (ic) / S(ita) S(it) T(ibi) T(erra) L(evis).

61. (M.70) CLEMENS ARRO/NIS <F(ilius)> PARS [C]ARVIE.

62. (M.71) CAI...RA SAI[LC]I F(ilia) AN(norum) / XI H(ic) S(ita) [T(ibi) T(erra) L(evis)].

63. (M.72) AISVS / SEMELI F(ilius) AN(norum) / L ... H(ic) T(ibi) T(erra) / L(evis).

64. (M.73) ...ClO/ TANCI/NI <F(ilio)> AN/N(orum) XL/H(ic) s(itus) $\mathrm{S}$ (it) $\mathrm{T}$ (ibi) / T(erra) L(evis). 


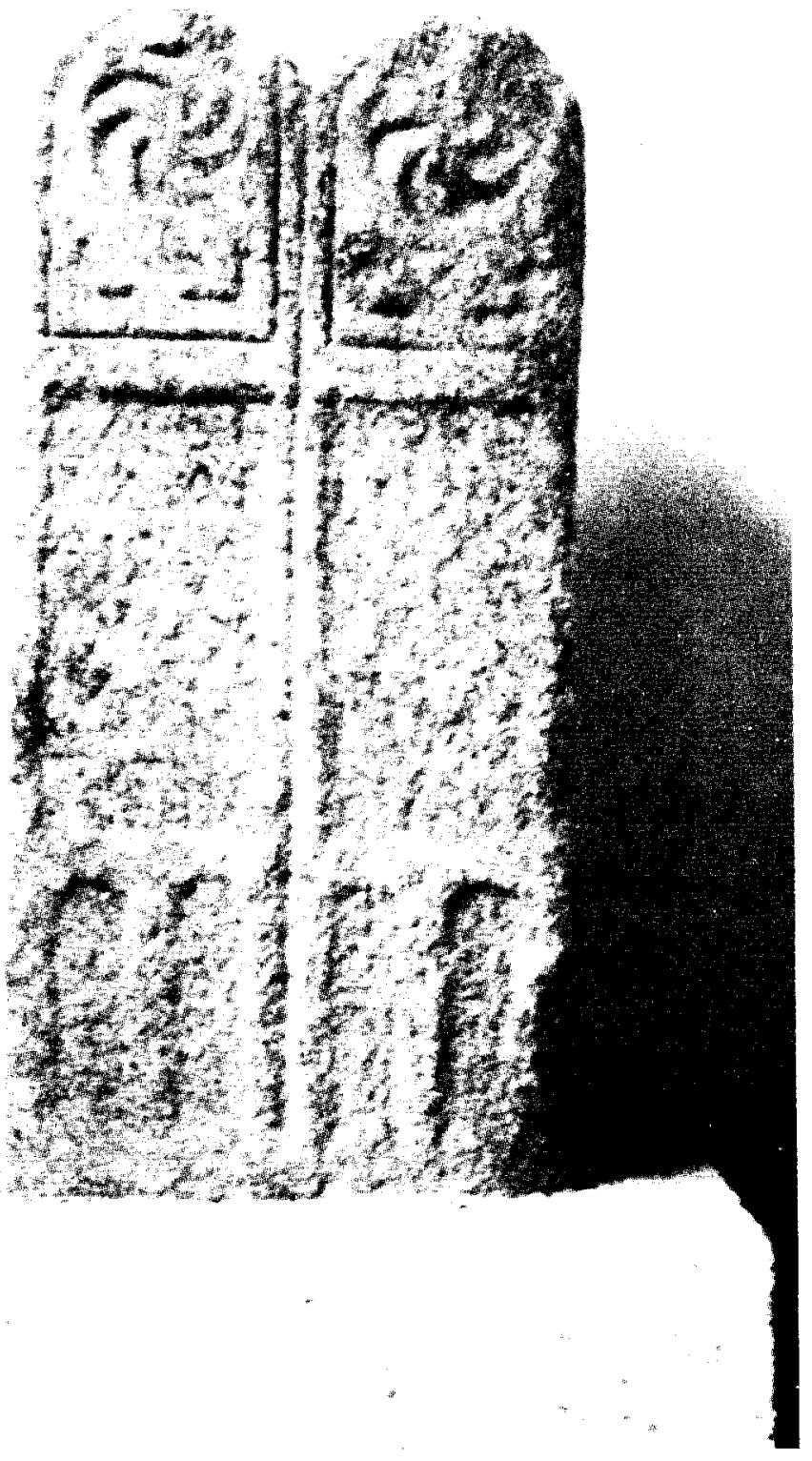

Fig. 10. Insc. n." 40. 
65. (M.74) $D$ (iis) $M$ (anibus) $S$ (acrum) / LEA/...

66. (M.75) .../...H(ic) S(itus ?)/ E(st) S(it) T(ibi) T(erra)L(evis).

67. (M.76) V... IVLII <F(ilius ?) > / ANNOR/VM XXXX / H(ic) S(itus ?) $S$ (it) $T$ (ibi) $T$ (erra) L(evis).

68. (M.77) [RE]BVR(RUS) [REB]/N[RRI] FI(ilius ) / AN(norum) LX / $\mathrm{H}$ (ic) S(itus) S(it) $\mathrm{T}$ (ibi) T(erra) L(evis).

N.B.: Las inscripciones numeradas del 1 al 28 pertenecen al conjunto de Medina del Campo. Vid. Mañanes, t.; hernández Guerra, L., y Jiménez dE Furundarena, A., "Un conjunto Epigráfico Inédito de Medina del Campo (Valladolid)", HA, n. ${ }^{\circ} \mathrm{XVI}, 1992$, págs. 273-308. Las numeradas del 29 al 68 pertenecen a Maluquer De Motes, J., Carta Arqueológica de España. Salamanca. Salamanca 1956, págs. 135-137, y su numeración viene indicada entre paréntesis como M. 38-77. 